\title{
Smart irrigation system based on IoT
}

\author{
Arushi Dheer \\ Information Technology \\ Maharaja Agrasen Institute of Technology \\ Delhi, India \\ arushidheer21@gmail.com
}

\author{
M.L.Sharma \\ Information Technology \\ Maharaja Agrasen Institute of Technology \\ Delhi, India \\ mlsharma@mait.ac.in
}

\author{
Krishna Chandra Tripathi \\ Information Technology \\ Maharaja Agrasen Institute of Technology \\ Delhi, India \\ kctripathi@mait.ac.in
}

\section{ABSTRACT}

Agriculture is the backbone of the Indian economy. The Indian agriculture sector accounts for 18\% of the gross domestic product and employs nearly $50 \%$ of the country's workforce, with increasing population, water shortage and ever-growing demand for food. Since the acres of land available for cultivation remains unchanged, it is critical that we take steps towards increasing productivity and optimizing water usage to increase yield from the land currently available for cultivation. Soil Analysis has become an essential factor for effective cultivation. The need for the automated irrigation system is to overcome over-irrigation and under-irrigation.[1] This research paper proposes an automated irrigation system using Arduino microcontroller, which is cost-effective and can be used on a farm field or average home garden. IoT is an upcoming technology with huge prospects. IoT is a technology which connects things, people, applications, data. Internet of Things (IoT)is a shared network of objects or things which can interact with each other provided the Internet connection - using this technology to implement this system at a lower scale to act as a base model. With the implementation of this project at a large scale, it could bring a significant change in the overall yield and water consumption in agriculture.

\section{INTRODUCTION}

With an increasing population and rising demand for food, we must take understand the need to make our agricultural systems smart and more reliable.

IoT makes everyday objects 'smart' by enabling them to transmit data and automate tasks without requiring any manual intervention.[2]

With the help of IoT, it has become possible to connect the sensors to the internet. We hope to provide soil analysis using various sensors with IoT anywhere. There are various parameters available for analysis, such as temperature, humidity, $\mathrm{pH}$, respiration, textures, Etc. Testing all the parameters is not feasible as we can achieve at the same results using fewer parameters as well [3]. In this paper, we have used humidity, temperature, and soil moisture. The brain of the model is Arduino Uno microcontroller which is connected to all the components in the model. The need to 
develop an automated irrigation system is to increase yield, reduce excessive water consumption, get real-time updates regarding the conditions of the soil and the ability to react according to the data received without any manual intervention. Since this is a small-scale model, this is ideal for a home garden. Implementing this system in a house will make sure the plants have adequate volume of water at all times, even when the owners are away at work or a vacation, the plants will remain healthy. In most regions of the country, irrigation is done using traditional methods such as sprinkling and drip irrigation which are inconvenient and cause excessive water consumption [4].

Implementation of a smart irrigation system also prevents over-irrigation and -under-irrigation. This model uses Things Speak as an IoT platform. There are other technologies available as well through which one can develop a similar model. Some testing methods used platforms like Losant, Etc to display the result in the form of graphical representation and then transferred readings via SMS. Some systems used hardware like Bluetooth or Zigbee to transfer results to the user's mobile which, when connected to the internet, uploaded the readings to the server and then gave an analysis on the readings [5]. Smart irrigation system using raspberry pi microcontroller is also one of the technologies proposed and implement before, but that increases the cost of the project.

\section{METHODOLOGY}

An automated irrigation system based on cloud and Arduino is proposed to optimize water consumption in irrigation and assist the farmer in monitoring the field from anywhere. The model of the system is illustrated in fig 1 . The model is made of two sensors, one for moisture and one for temperature and humidity.

These sensors provide real-time information regarding the characteristics of the soil to the ThingsSpeak platform via wi-fi module. This information is then processed by Arduino Uno microcontroller. The Arduino Uno microcontroller has been programmed with an algorithm with soil moisture readings to take the decide whether to irrigate or not to irrigate. This system takes in real-time information about the soil, processes it and then takes the decision if it should switch the motor ON or not.

\section{THE HARDWARE USED IN THIS MODEL:}

\section{1) ARDUINO UNO}

The Microcontroller used here is an Arduino UNO. The UNO is a Microcontroller board based on ATMEGA 328P. The ATMEGA 328P has $32 \mathrm{kB}$ of flash memory for storing code.[6] The board includes 14 digital input and output pins, six analogue inputs, $16 \mathrm{MHz}$ quartz crystal, USB, an ICSP 


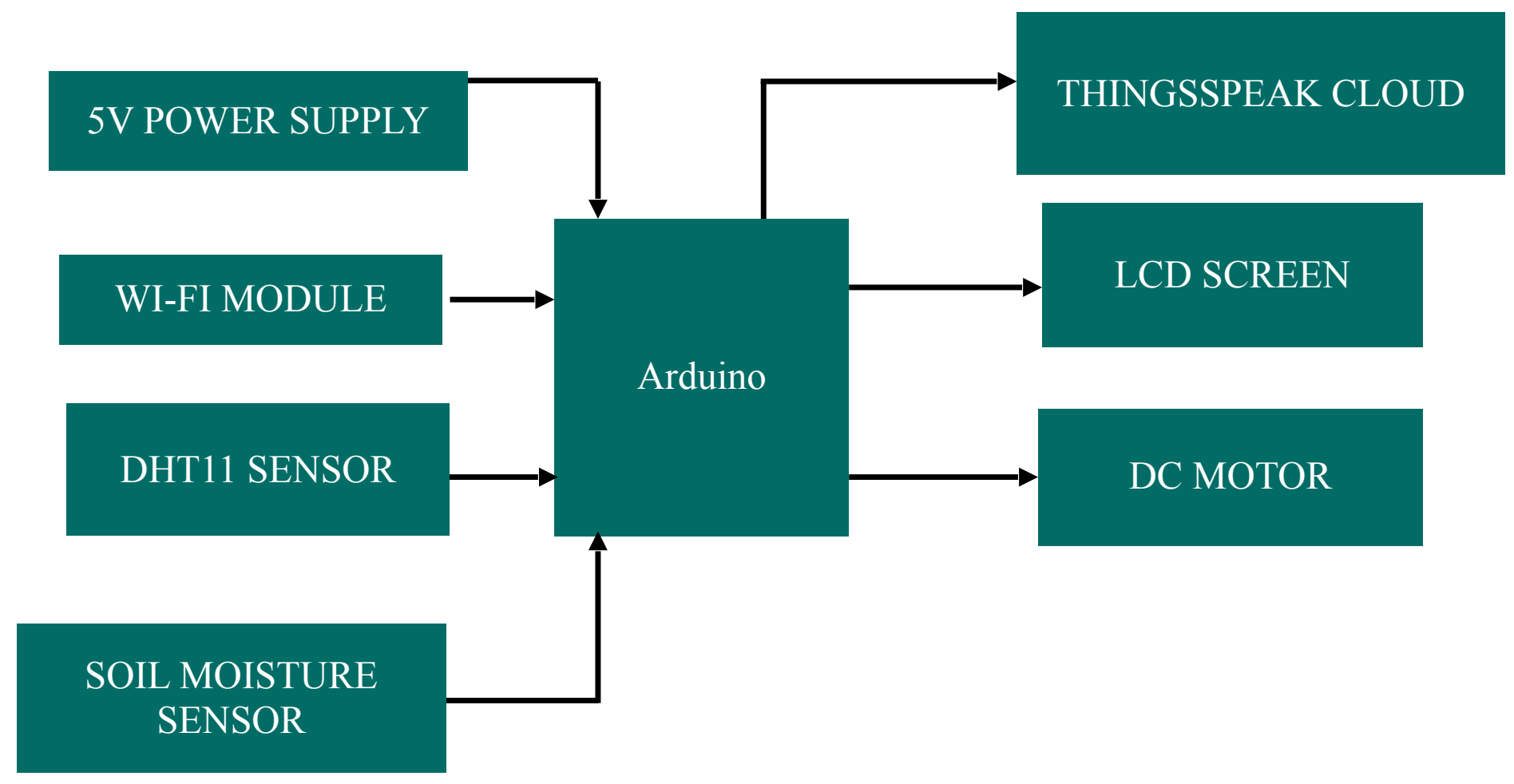

Fig 1 : proposed system diagram

circuit and a reset button. The UNO needs to be programmed with the Arduino software. It is an open-source microcontroller, which is the brain of the model. Each of the 14 digital pins on the Arduino Uno can be used as an input or output,by using pinMode(), digitalWrite(), and digitalRead() functions. They function at 5 volts. Each pin can provide or receive a maximum of 40 $\mathrm{mA}$ and has an internal pull-up resistor of 20-50 kOhms. The Arduino ethernet shield connects the Arduino board in mere minutes.

\section{2) IOT-INTERNET OF THINGS}

IoT is a new emerging technology. It is targeted to connect everything that can be controllable and needs to be monitored. IoT, is a system of interrelated computing devices, mechanical and digital machines, objects, animals or people that are provided with unique identifiers (UIDs) and the ability to transfer data over a network without requiring human-to-human or human-to-computer interaction. The internet of things helps people live and work smarter, as well as gain complete control over their lives. IoT provides businesses with a real-time look into how their systems really work, delivering insights into everything from the performance of machines to supply chain and logistics operations.[7]

An IoT ecosystem consists of web-enabled smart devices that make use of embedded systems, such as processors, sensors and communication hardware, which collect, send and act on data they acquire from their environments. IoT device shares the sensor data they collected by connecting to an IoT gateway or some other edge device where data is either sent to the cloud to be analyzed or is 
analyzed locally. In this project, the IoT gateway used is Things Speak and Arduino Uno board. (figure 2)

IoT devices are "embedded" within other devices in order to provide enhanced functionality without exposing the user to the complexities of a computer. Embedded systems provide real-time computing, low power consumption, low maintenance and high availability.

\section{3)DHT11 SENSOR - TEMPERATURE AND HUMIDITY SENSOR}

The DHT11 Temperature and Humidity sensor are used. The total amount of water vapour in the air is defined as a measure of humidity. The relative humidity is calculated because when there are changes in temperature, relative humidity also changes. The temperature and humidity changes occur before and after irrigation. The number of water droplets in air has increased after irrigation. This causes a decrease in temperature, which in turn increases the relative humidity of the surroundings. The temperature and humidity reading is often notified to the user so that the user can be able to know the field conditions from anywhere. The temperature and humidity sensor can also be used in greenhouses.[8](figure 3)

\section{4) THINGSSPEAK PLATFORM}

It is an IoT analytics platform service that allows you to aggregate, visualize and analyze live data streams in the cloud. ThingSpeak provides instant visualizations of data posted by your devices to ThingSpeak. With the ability to execute MATLAB ${ }^{\circledR}$ code in ThingSpeak, you can perform online analysis and processing of the data as it comes in. [9] (figure 4)

\section{5) WI-FI MODULE- ESP8266}

It is a self-contained SOC with integrated TCP/IP protocol stack that can give any microcontroller access to your wi-fi network. The serial module works in both directions. It uses a TX/RX serial link to receive and send data.[10]

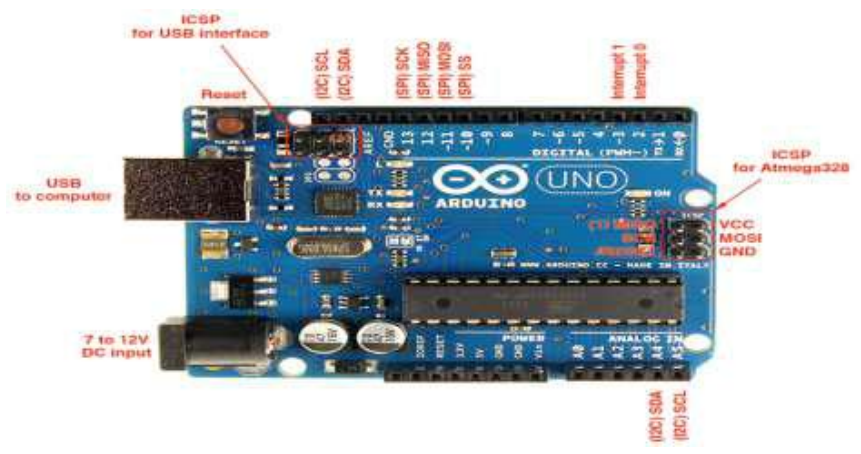

Fig 2: arduino uno board

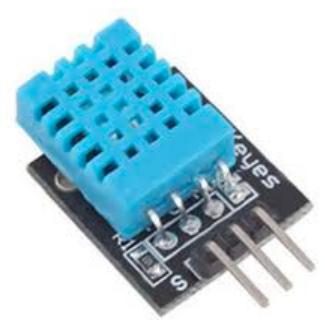

Fig 3: DHT11 sensor 


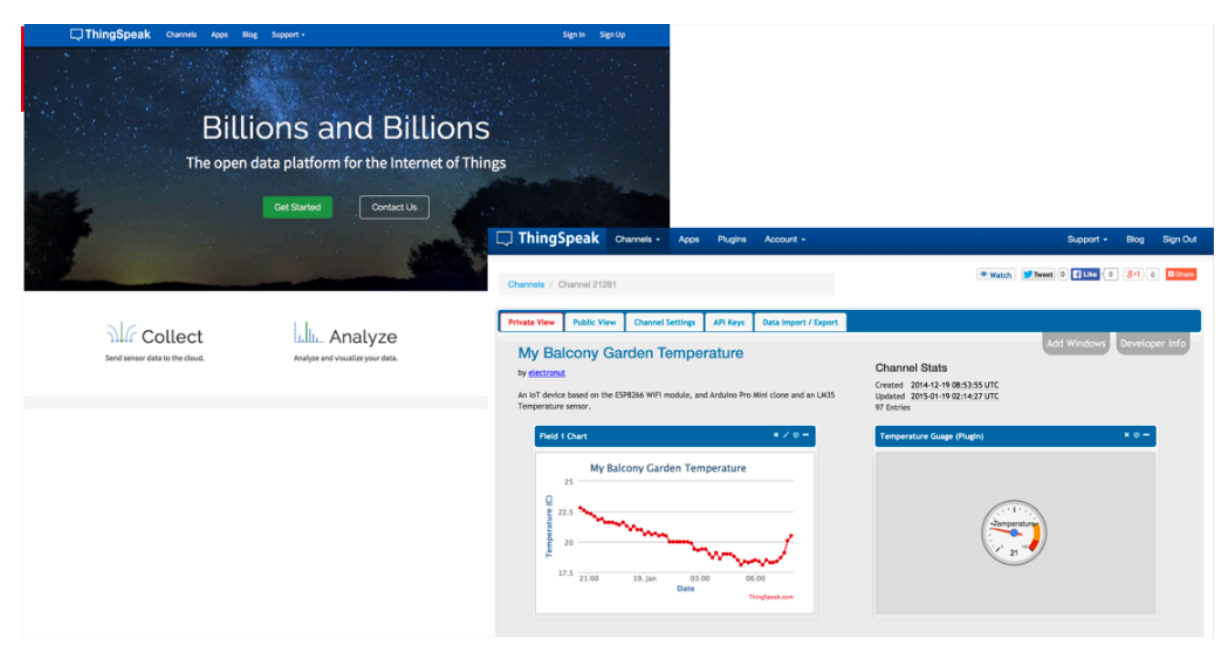

Fig 4: things speak platform

\section{IMPLEMENTATION}

The realization of this work is illustrated in fig 6 . The circuit diagram for the connections made is illustrated in figure 5.

The first step is to create a math work account on ThingsSpeak platform. Then we create a channel named sensor monitoring, associated with an ID and password. Then we connect the system through the wi-fi module esp8266, to our wi-fi and feed in the details of our wi-fi connection in the Arduino Uno microcontroller for the exchange of data (fig). Now the sensor readings are uploaded on both the ThingsSpeak channel as well as the Arduino Uno board. The board then decides based on the reading if the motor needs to be switched ON or OFF. The board is programmed to switch ON the DC motor when the soil moisture reading goes below 50 and switch the Motor OFF when the soil moisture reading goes above 70 . Since this is a base model for future applications, the motor used is a DC motor which works between $6 \mathrm{~V}$ and $12 \mathrm{~V}$ and can pump up to 30-40 litres of water. There is a $5 \mathrm{~V}$ supply made by connecting two capacitors, one resistor and one $7805 \mathrm{IC}$. This is done so as to supply low voltage to those parts of the circuit which don't need direct $12 \mathrm{~V}$. There are two sensors connected to the Arduino Uno board: DHT11(temperature and humidity sensor) and soil moisture sensor. The LCD screen is connected to the Arduino board and displays all the results. 

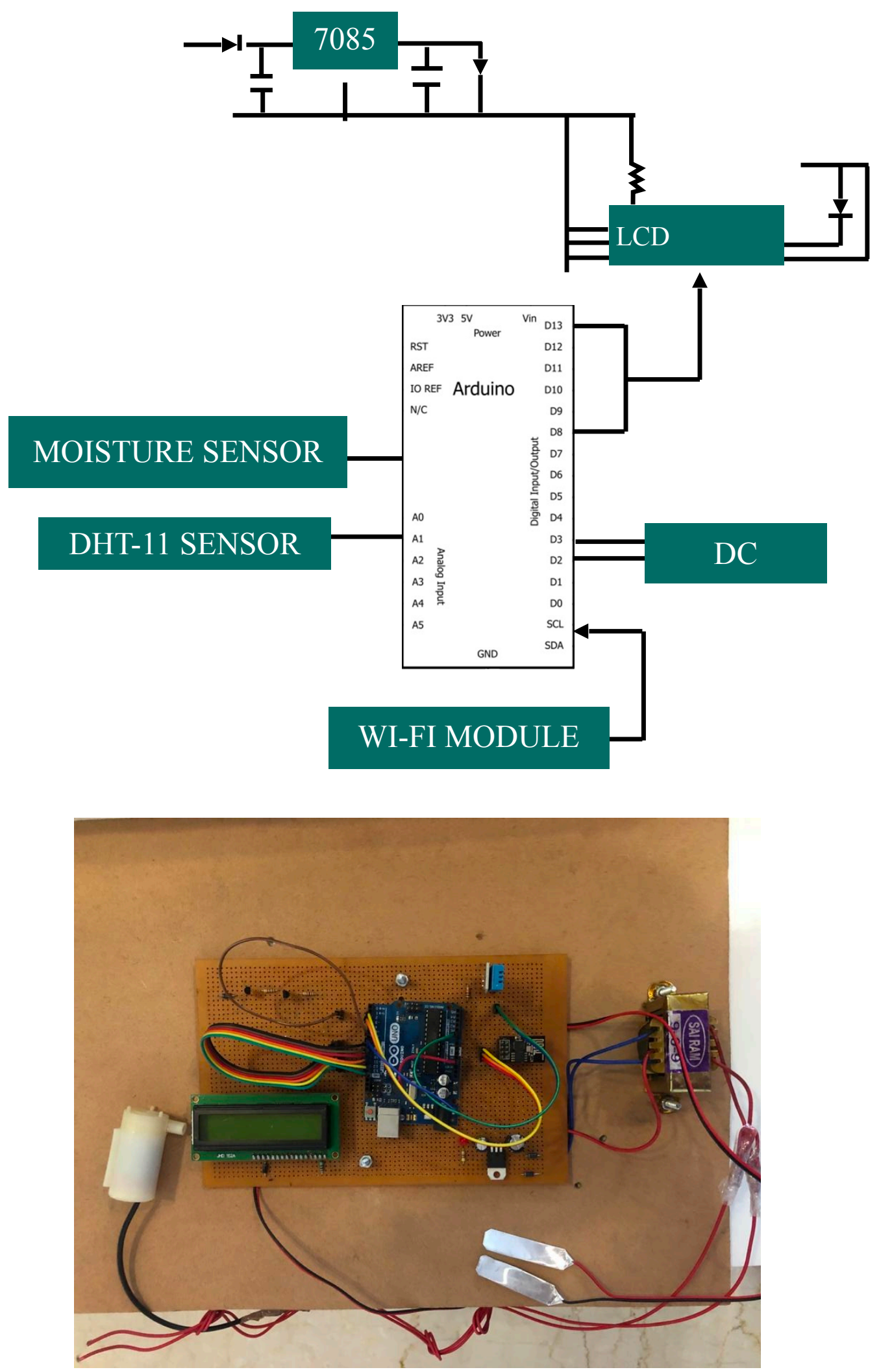

Fig 6: system model 


\section{RESULT AND DISCUSSION}

The following figures 7, 8, 9 and 10 show the readings taken by the sensors.

Fig 7 shows that the channel has been created, figures 8,9,10 display the graph plotted from the different readings uploaded from the temperature, humidity and soil moisture sensor. When the readings are uploaded if the soil moisture reading is less than 70 then the motor starts pumping water and as soon as the reading above 70 is uploaded the motor is switched off.

\section{$\square$ ThingSpeak}

\section{Sensor Monitoring}

Channel ID: 1214908

Author: mwa0000020174686

Access: Private

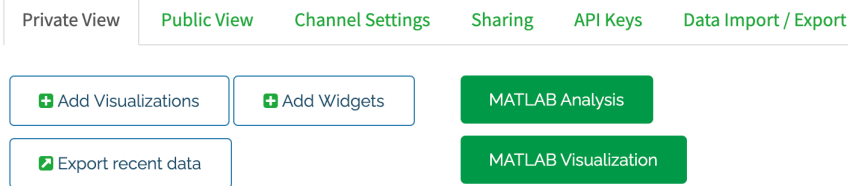

Fig 7: sensor monitoring

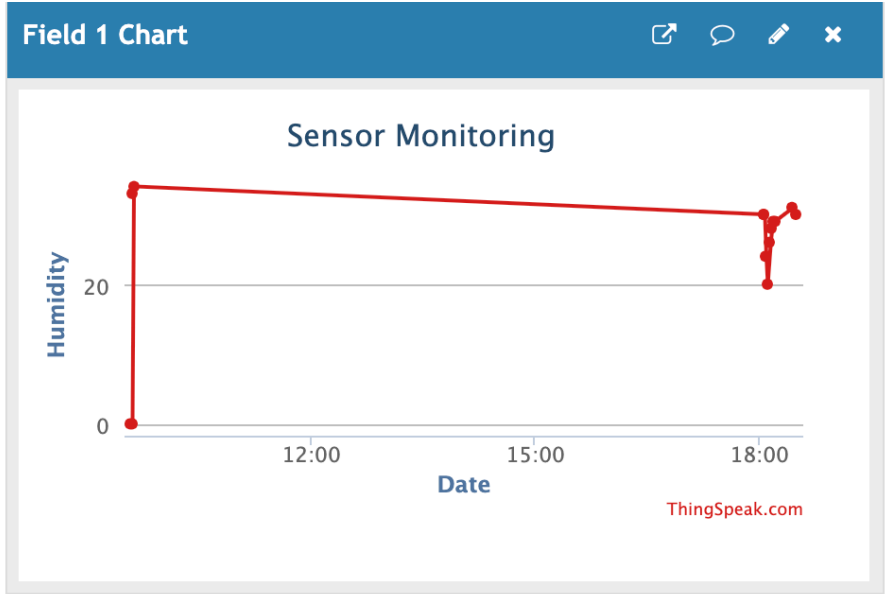

Fig 8: humidity
Sensor Monitoring

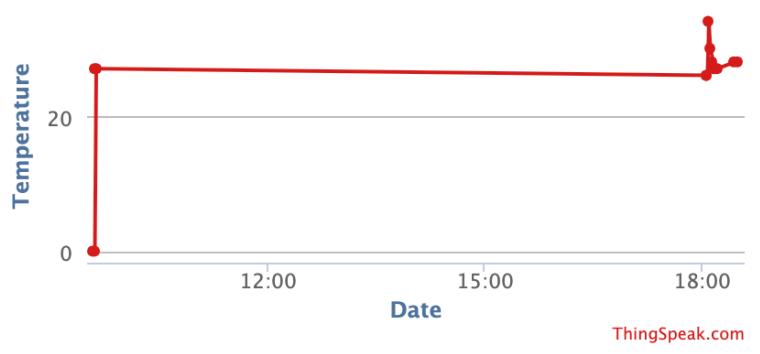

Fig 9: temperature

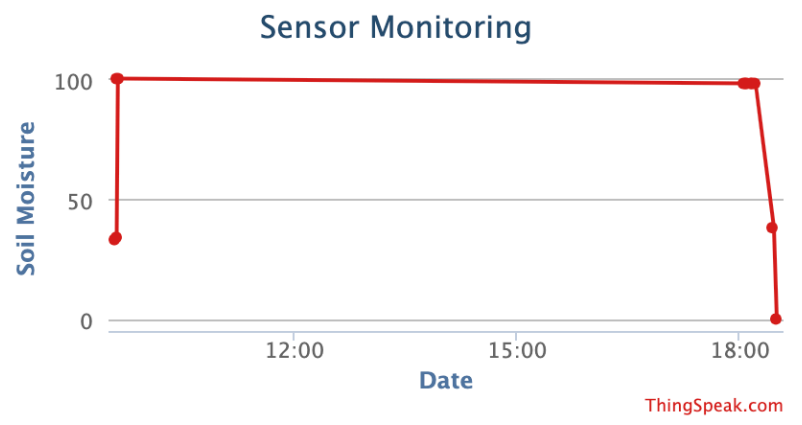

Fig 10: soil misture 


\section{CONCLUSION}

In this paper, an intelligent irrigation system based on IoT was implemented. A channel was created on an open-source IoT platform. The system can be used to irrigate a small garden or crops grown in a home environment. The DC motor used can pump approximately 30-40 litres of water continuously. This is a base model for future applications in a large field. 


\section{REFERENCES}

[1] Amruta ugankar, "What is IoT and Why is it Important? 9 IoT Statistics to Watch Out For" $<$ www.built.io/blog/what-is-iot-and-why-is-it-important-9-iot-statistics-to-watch-out-for $>$

[2] R.Nandhini, S.poovizhi, Priyanka Jose, R. Ranjitha, Dr.S.Anila, "arduino based smart irrigation system using Io T" $<$ www.researchgate.net/profile/Anila_Satish/publication/>

[3] [Hridesh Shah, Dhruv Shah, Jeet Shah, Akshat Shah, Karan Shah AndKrupalVora. (2018); IOT BASED SOIL TESTING. Int. J. of Adv. Res. 6 (Nov). 974-979] (ISSN 2320-5407). www.journalijar.com

[4] P. Rajalakshmi and S. Devi Mahalakshmi, "IOT based crop-field monitoring and irrigation automation," 2016 10th International Conference on Intelligent Systems and Control (ISCO), Coimbatore, 2016, pp. 1-6, doi: 10.1109/ISCO.2016.7726900.

[5] hridesh shah ,dhruv shah, jeet shah ,akshat shah, Karan shah and Krupal vora , "iot based soil testing" $<$ www.journalijar.com/uploads/746_IJAR-25178.pdf $>$

[6] Hassan, Aslinda \& Sheng, Siah \& Md Shah, Wahidah \& Bahaman, Nazrulazhar. (2018). An Automated Irrigation System Using Arduino Micro controller.

[7] Margaret Rouse, Alexander Gillis, Linda Rosencrance, Sharon Shea and Ivy Wigmore, 'internet of things' $<$ internetofthingsagenda.techtarget.com/definition/Internet-of-Things-IoT>

[8] R. N. Rao and B. Sridhar, "IoT based smart crop-field monitoring and automation irrigation system," 2018 2nd International Conference on Inventive Systems and Control (ICISC), Coimbatore, 2018, pp. 478-483, doi: 10.1109/ICISC.2018.8399118.

[9] https://thingspeak.com/pages/learn_more

[10] <WiFi module- ESP8266-WRL-13678- SparkFUN electronics $>$ [en. $\quad$ ligne]. Disponible sur: https://www.sparkfun.com/products/13678. [consulté le: 04-août-2018]. 